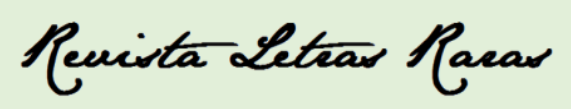

ISSN: 2317-2347 - Vol. 5, Ano 5, № 3 - 2016

\title{
Um guia do imponderável: como preparar o trabalho de campo
}

\author{
Priscilla Alyne Sumaio Soares*
}

\section{Resenha do Livro:}

SAKEL, Jeanette \& EVERETT, Daniel L. Linguistic Fieldwork: a student guide. Cambridge, New York: Cambridge University Press, 2012.

De acordo com Jeanette Sakel e Daniel Everett, o trabalho de campo é essencial para expandir nosso conhecimento sobre como a linguagem funciona, isso porque não estamos aptos a ter novas ideias teorizando sozinhos e, portanto, dados reais são necessários para tornar descobertas válidas. Assim sendo, o trabalho de campo é indispensável para o desenvolvimento teórico. Isso é claro para muitos pesquisadores, mas como realizar o trabalho de campo? Como obter sucesso nessa empreitada, em que lidamos sempre com a sombra do desconhecido, e mesmo com a possibilidade do imponderável? Este livro, com saborosos relatos de experientes e renomados pesquisadores, e com ótimo posicionamento sobre a bibliografia na área, pode nos ajudar nisso, sejamos estudantes ou não.

Discutindo o que vem a ser "trabalho de campo", os autores explicam as diferenças entre um trabalho de campo prototípico e um trabalho de campo nãoprototípico. Eles apontam que grande parte das pessoas pensa nessa atividade de pesquisa como um trabalho envolvendo coletar dados de línguas em risco de extinção em um lugar remoto e geralmente "exótico", mas ponderam que nem sempre é assim.

Citando Hyman (2001), explicam que trabalho de campo prototípico envolve mesmo a pesquisa com falantes em um lugar pequeno e distante, com língua e cultura desconhecidas pelo pesquisador, por um longo período de tempo. Em tal situação, a língua é falada em seu contexto natural, os dados são naturais e a motivação para conduzir o trabalho de campo é inteiramente impulsionada pela língua. O oposto disso é apresentado: trabalho de campo não-prototípico, em que os linguistas utilizariam seu

\footnotetext{
* Doutoranda no Programa de Línguística e Língua Portuguesa, da UNESP, Araraquara, SP. Bolsista CAPES. Membro do Grupo LINBRA. E-mail: pri_sumaio@ hotmail.com.
} 


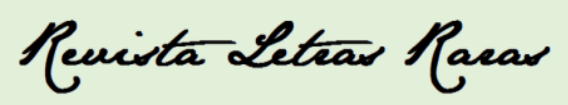

ISSN: 2317-2347 - Vol. 5, Ano 5, № 3 - 2016

conhecimento de suas próprias línguas ou observariam falantes em um lugar grande e próximo de onde moram. Nestes casos, o trabalho de campo duraria apenas pouco tempo, sendo a língua estudada conhecida pelos investigadores. No caso do linguista levando em conta seus conhecimentos como falante nativo, o objeto de estudo, em geral, seria o sistema formal da língua, sendo os dados controlados e a análise condicionada a uma teoria.

Contudo, ampliando a visão do que seja um trabalho de coleta de dados linguísticos, a definição dos próprios autores é muito interessante: segundo eles, "trabalho de campo descreve a atividade de um pesquisador analisando sistematicamente partes de uma língua, usualmente outra que sua própria língua nativa, e usualmente dentro de uma comunidade de falantes daquela língua"1 (SAKEL; EVERETT, 2012, p. 5). Com isso, eles compreendem trabalho de campo não só da forma prototípica, mas englobando trabalhos envolvendo as mais diferentes situações: trabalho com falantes da mesma língua do pesquisador; trabalho com falantes pertencentes à mesma comunidade do pesquisador; e ainda grande gama de outras variações. Sua definição também mostra que o estudo será sempre de uma parte da língua, sem a pretensão da exaustividade, que é inalcançável. Assim, afirmam que quando alguém diz que está "descrevendo a gramática de uma língua" na verdade está querendo dizer que está descrevendo partes dessa língua, em determinado momento temporal, com determinados dados, que geralmente são coletados na comunidade de fala (embora se tenha por vezes um trabalho de campo com um falante fora de sua comunidade).

Uma técnica muito válida que os autores sugerem usar para iniciar uma coleta de dados é pedir que o informante descreva a si mesmo. Isso possibilita conhecer mais sobre o povo com quem o pesquisador vai trabalhar e a maioria dos entrevistados poderá falar alguns minutos sobre esse tópico, o que renderá uma considerável quantidade de dados inicial. Contudo, pensamos que, por vezes, este procedimento deva ser redimensionado, caso falar sobre si mesmo seja um problema para o informante naquele momento, e insistir na atividade seria causar constrangimento; isso devido a questões que não compreendemos, dado nosso contato por vezes inicial com o povo.

\footnotetext{
${ }^{1}$ Tradução minha.
} 


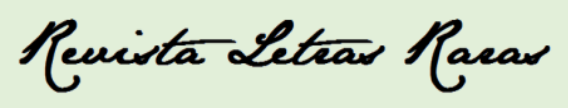

ISSN: 2317-2347 - Vol. 5, Ano 5, № 3 - 2016

Outra ideia dos autores é mostrar aos informantes cartoons ocultando a fala dos personagens, para que eles possam fazer a narrativa da história. Isso ajudaria a obter dados com o mínimo possível de influência de outras línguas, ou seja, sem induções provenientes da língua do pesquisador ou do intérprete, o que é valioso em contextos em que se sabe existir o uso de diversas línguas. Inclusive, serviria para comprovar os conhecimentos de um falante, deixando-o mais livre para usar seu vernáculo. Mas, como língua e cultura se imbricam, podemos questionar se o cartoon apresentado seria compreendido pelo falante, uma vez que poderia se referir a coisas, fatos totalmente estranhos para ele, por não pertencerem a sua cultura.

Sakel e Everett falam também sobre a distinção entre trabalho de campo bilíngue e monolíngue. Eles dizem que o trabalho de campo monolíngue requer do linguista falar e entender o suficiente da língua estudada para que os dados tenham sentido. Isso dispensa o uso de língua franca, mas pode, segundo eles, parecer um trabalho com hieróglifos de línguas perdidas - só que sem uma pedra de Rosetta. Nesse sentido, é notável o trabalho de Everett com os pirahã, por exemplo, que sempre foram tidos como monolíngues, e com isso ele precisou aprender a língua através de um método, bem dominado por Pike, por exemplo, que envolvia apontar inicialmente para objetos e obter seus nomes, realizar pequenas ações, como derrubar uma pedra, e, por gestos, perguntar como se fala isso. Embora complexo, este método tem a vantagem de tornar o pesquisador minimamente proficiente como falante da língua estudada. Esta, inclusive, seria uma meta para todo pesquisador de uma língua.

Já o trabalho de campo bilíngue significa que o pesquisador usará uma língua diferente da língua alvo para se comunicar com os falantes, o que marca a existência de uma língua franca. Esta pode ser a própria língua materna do linguista, ou a língua que ele aprendeu com o intuito de estar apto a realizar seu trabalho de campo, e que ambos ele e o informante - sabem o suficiente para se comunicarem bem. De qualquer forma, o linguista precisa falar a língua franca suficientemente bem para estar apto a se comunicar, por provavelmente não conhecer nada, ou ter um conhecimento muito restrito da língua alvo.

Quanto a isso, os autores explicam que o problema de se usar uma língua franca é que isso pode fazer o pesquisador enxergar a língua alvo por meio de "lentes embaçadas", e mesmo, o pesquisador pode não entender todas as sutilezas da língua 


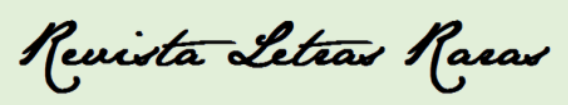

ISSN: 2317-2347 - Vol. 5, Ano 5, № 3 - 2016

alvo, simplesmente porque elas não existem na língua franca. Inclusive, alertam que os informantes irão apresentar interferência da língua franca em sua língua se aquela é usada como uma língua de trabalho. Como exemplo, se o pesquisador for perguntar como se traduz "Eu gostaria de fazer uma caminhada hoje", o informante pode traduzir isso usando a mesma ordem sintática da língua franca. Essa ordem sintática resultante pode ser aceitável na língua alvo, mas pode não ser a ordem sintática não-marcada dela. Por essa dentre outras razões é importante usar uma variedade de métodos ao coletar dados, e não apenas elicitação, em particular em trabalhos bilíngues (SAKEL; EVERETT, 2012, p. 28).

Outro motivo apontado para fazer um trabalho monolíngue é mostrar profundo respeito pela língua que se estuda. Isso emergiria quando o povo em questão percebesse que o pesquisador estava evitando línguas que podem ser vistas como "línguas de dominação", e podemos compreender esta situação, mas ponderamos aqui que ela não é recorrente, uma vez que a diglossia que possa existir nem sempre faz pensar em subjugação/ dominação de um povo sobre outro. Uma situação de diálogo em língua majoritária, que poderia parecer atitude de opressão linguística, do meu ponto de vista, talvez possa ser seja um diálogo proveitoso para seus propósitos, do ponto de vista do falante.

E finalmente, outra razão apresentada para se trabalhar sem uso de língua franca é o fato de não se ter outra escolha. Isso aconteceu com um dos autores, Everett, quando trabalhou com os Pirahã, no Brasil, como ele demonstra também em seu documentário “The Amazon code", e em livros como D'ont sleep, there are snakes, um best seller, e Language, the cultural tool.

Pensando no primeiro contato, os autores dizem que ele é crucial, ao conhecer o povo com que o pesquisador trabalhará. A primeira impressão será importante no relacionamento, poderá marcar toda pesquisa futura, classificando o pesquisador como confiável ou não, tendo delimitados os seus propósitos e seu esforço em ter proficiência na língua. Assim, recomendam o preparo prévio, ler tudo o que está publicado sobre esse povo e sua língua, sobre sua situação linguística Eles afirmam que, linguisticamente, o pesquisador impressiona mais positivamente se aprender logo frases na língua. 


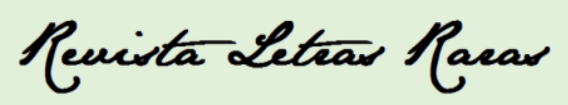

ISSN: 2317-2347 - Vol. 5, Ano 5, № 3 - 2016

Assim, recomendam ouvir e procurar imitar para aprender o que os falantes dizem enquanto já se desfazem as malas. Dizem também que algumas vezes é difícil saber como agir. Por exemplo, se alguém te pedir algo que é seu e você der, se você vai ser visto como "bobo" e vai ser sempre obrigado a dar suas coisas, ou se vai ser visto como uma boa pessoa e não vão mais te pedir nada. Uma maneira de lidar com isso é observando outros, perguntando a outros, lendo e aprendendo com experiências de outros.

O primeiro dia não é apenas de aprendizado linguístico. Também é dia de desenhar mapas da comunidade, aprender quem é o líder local, se existir um e também falar com ele. Se possível, falar com o líder antes de ir e explicar seus objetivos e saber as aspirações dele e da comunidade. O linguista deve saber também como deve pagar por seus gastos, onde conseguir água, etc. Fotos também ficam melhores nesse estágio. Também é hora de aprender frases metalinguísticas como "o que é isso"?, "o que ela está fazendo"?, e "quando você vai?". Sakel e Everett aconselham aproveitar esse dia ao máximo, pois ele nunca vai se repetir, e os outros dias não serão nem um pouco parecidos com ele.

Os autores alertam também os pesquisadores sobre os possíveis conflitos de interesses. Eles colocam que, sem quererem ser pessimistas, terão que mencionar o cenário de conflito de interesses que linguistas que fazem trabalho de campo podem encontrar, de tempos em tempos. Sakel e Everett tratam, então, de quatro tipos comuns de conflito, que podem prejudicar um trabalho de campo: 1. Problemas com falantes 2. Problemas com a comunidade 3. Problemas com organizações, e 4. Problemas com outros pesquisadores. Sabemos que conflitos podem existir com grupos dentro da comunidade e, inclusive, com outros pesquisadores na área. Por isso, saber administrálos é algo valioso e os autores nos alertam sobre isso.

Neste texto, apontamos apenas alguns aspectos da obra em foco, que pode auxiliar, e muito, o trabalho de jovens pesquisadores, ou de pesquisadores mais experientes. Sem dúvida alguma, sua contribuição à área é grande e constitui leitura agradável, com abordagem fluente e atual.

\section{REFERÊNCIAS}




\section{Reuista Leteras Racar}

ISSN: 2317-2347 - Vol. 5, Ano 5, № 3 - 2016

EVERETT, D. L. Language: The Cultural Tool. New York: Pantheon Books, 2012

EVERETT, D. L. The Amazon code - the grammar of happiness. Smithsonian Channel, Essential Media and Entertainment Pty ltd. Screen Australia and Screen NSW 2012

Recebido em: 08/12/2016

Aceito em:12/12/2016 